\title{
The effect of chronic peripheral nesfatin-1 application on blood pressure in normal and chronic restraint stressed rats: related with circulating level of blood pressure regulators
}

\author{
Ceylan Ayada ${ }^{1}$, Günfer Turgut ${ }^{2}$, Sebahat Turgut ${ }^{2}$ and Zuhal Güçlü ${ }^{3}$ \\ ${ }^{1}$ Department of Physiology, Faculty of Medicine, University of Dumlupınar, Kütahya, Turkey \\ ${ }^{2}$ Department of Physiology, Faculty of Medicine, University of Pamukkale, Denizli, Turkey \\ ${ }^{3}$ Experimental Research Unit, University of Pamukkale, Denizli, Turkey
}

\begin{abstract}
Nesfatin is a peptide secreted by peripheral tissues, central and peripheral nervous system. It is involved in the regulation of homeostasis. Although the effects of nesfatin-1 on nutrition have been studied widely in the literature, the mechanisms of nesfatin-1 action and also relations with other physiological parameters are still not clarified well. We aimed to investigate the effect of peripheral chronic nesfatin-1 application on blood pressure regulation in normal and in rats exposed to restraint immobilization stress. In our study, three month-old male Wistar rats were used. Rats were divided into 4 groups as Control, Stress, Control+Nesfatin-1, Nesfatin-1+Stress. Angiotensinogen, angiotensin converting enzyme 2, angiotensin II, endothelin-1, endothelial nitric oxide synthase, aldosterone, cortisol, nesfatin-1 levels were determined in plasma samples by ELISA. Our results have shown that chronic peripheral nesfatin-1 administration increases blood pressure in normal and in rats exposed to chronic restraint stress. Effect of nesfatin-1 on circulating level of angiotensinogen, angiotensin converting enzyme 2, angiotensin II, endothelin-1, endothelial nitric oxide synthase, aldosterone and cortisol has been identified. We can conclude that elevated high blood pressure after chronic peripheral nesfatin-1 administration in rats exposed to chronic restraint stress may be related to decreased plasma level of endothelial nitric oxide synthase concentration.
\end{abstract}

Key words: Nesfatin-1 - Renin-angiotensin-aldosterone system (RAAS) - Cortisol - Endothelin-1 - Endothelial nitric oxide synthase (eNOS)

\section{Introduction}

Hypertension is very important worldwide public health challenge because of its high frequency and concomitant risks of cardiovascular disease. It has been identified as a leading risk factor for mortality. The high prevalence of hypertension worldwide has contributed to the present pandemic of stroke and cardiovascular diseases. The rapid rise in the mortality of cardiovascular diseases is attributable mainly to changes in environmental risk factors, such as diet and physical activity (Kearney et al. 2005; Agyemang et al. 2007).

Correspondence to: Ceylan Ayada, Dumlupınar University, Faculty of Medicine, Department of Physiology, Kütahya, Turkey

E-mail: ceylanayada@yahoo.com
Stressor can be broadly defined as an actual or anticipated disruption of homeostasis or an anticipated threat to wellbeing. The survival and well-being of all species requires appropriate physiological responses to environmental and homeostatic challenges. The re-establishment and maintenance of homeostasis entails the coordinated activation and control of neuroendocrine and autonomic stress systems. The brain is the key organ for response to stress. That's why stressor-related information from all major sensory systems is conveyed to brain. Stress involves two-way communication between brain and cardiovascular, immune, and other systems via neural and endocrine mechanisms. Brain activates neural and endocrine systems to minimize the harmful effects of stress (McEwen 2007; Ulrich-Lai and Herman 2009). Acute and chronic stresses increase the cardiovascular responses. Thereby, stress contributes to the 
development of risk for hypertension and cardiovascular diseases, although the evidence is still inconclusive. It is generally accepted that stress-induced hypertension is due to the sequential increases in sympathoadrenal activity, norepinephrine and epinephrine release, and enhanced vascular tone; however, the long-lasting vasoconstriction induced by sympathetic nerve stimulation cannot be prevented by complete $\alpha$-adrenoreceptor blockade, suggesting that sympathetic nerve-mediated vasoconstriction may also be mediated by factors other than catecholamines (Han et al. 1998; Barbieri et al. 2012).

Nesfatin-1 is an 82 -amino-terminal fragment derived from the larger protein nucleobindin-2 (NUCB2) and is distributed in the central nervous system (CNS), implicated in the regulation of feeding, including the hypothalamic paraventricular nucleus (PVN), arcuate nucleus (ARC), lateral hypothalamic area and supraoptic nucleus (SON) (Oh-I et al. 2006). NUCB2 gene expression is significantly regulated by nutritional status, suggesting the role of nesfatin- 1 in energy homeostasis (Stengel and Taché 2010). Nesfatin-1 is localized in neurons of the hypothalamus and brain stem and colocalized with stress-related substances, corticotropinreleasing hormone $(\mathrm{CRH})$, oxytocin, proopiomelanocortin, noradrenaline (NA) and 5-hydroxytryptamine (5-HT). Intracerebroventricular (icv) administration of nesfatin-1 produces fear-related behaviors and potentiates stressorinduced increase in plasma adrenocorticotropic hormone (ACTH) and corticosterone levels in rats. It has been also shown that brain nesfatin-1 level is increased under stress conditions. These findings suggest that there should be possible cross-talks between nesfatin-1 and stress (Yoshida et al. 2010). Some other studies have indicated that central administration of nesfatin-1 increases blood pressure (BP) but the mechanism of action has not been clarified yet (Yosten and Samson 2009; Yamawaki et al. 2012). Nesfatin-1 suppresses feeding independently from the leptin pathway, and increases insulin secretion by activation of L-type $\mathrm{Ca}^{2+}$ channels in pancreatic islet beta cells (Shimizu et al. 2009; Nakata et al. 2011). Because of these effects of nesfatin-1, it became a popular therapeutic target in diseases such as obesity and diabetes mellitus that are considered as chronic stress factor for human body. That's why we hypothesized that possible hypertensive effect of nesfatin- 1 could lead serious health problems during the possible treatment procedures for various diseases. Thus, in present study experimental model have been preferred to be able to mimic human body in disease conditions. We have identified the effect of chronic peripheral nesfatin-1 application on BP regulation in normal and in rats exposed to chronic immobilization stress. Plasma level of angiotensinogen (AGT), angiotensin converting enzyme 2 (ACE2), angiotensin II (AngII), endothelin-1, endothelial nitric oxide synthase (eNOS), aldosterone, cortisol and nesfatin-1 which are components involved in regulation of BP were measured. We aimed to identify possible relationship between nesfatin-1, stress condition, BP and related effectors of BP.

\section{Materials and Methods}

\section{Animals and experimental conditions}

All experimental protocols conducted on animals were consistent with the National Institutes of Health Guidelines for the Care and Use of Laboratory Animals (NIH Publication No. 85-23) and approved by the Pamukkale University Ethics Committee of Animal Care and Usage. In this study three-months-old 28 male Wistar Albino rats weighing 298-397 g were used. They were reared under the supervision of a veterinarian, kept in a well-ventilated, noiseless environment, and allowed free access to food and water. The rats were housed in a room with controlled temperature (23 $\left.\pm 1^{\circ} \mathrm{C}\right)$ and relative humidity $(50 \pm 5 \%)$, and they were kept in transparent plastic cages $(42 \times 26 \times 15 \mathrm{~cm})$, each containing three or four rats, exposed to a 12:12 light/dark cycle.

\section{Experimental design}

The rats were randomly divided into four experimental groups $(n=7)$. The groups were described as; control (C) rats without any treatment, chronic restraint stressed (S) rats were placed in a specially built size-manipulable cabin for $2 \mathrm{~h}$ /day (between 10:00-12:00 A.M.) for 10 consecutive days without allowing water and food intake to be able to create the animal model of restraint stress (Vyas et al. 2002; Bhatia et al. 2011) without any injection, control+nesfatin-1 applied $(\mathrm{C}+\mathrm{N})$ rats were treated with rat nesfatin-1 segment $(0.25 \mathrm{nmol} / \mathrm{g}$ body weight i.p. injection $)$ during the 10 consecutive days (Shimizu et al. 2009), nesfatin-1 applied + chronic restraint stressed $(\mathrm{N}+\mathrm{S})$ rats were first treated with rat nesfatin-1 segment as in $\mathrm{C}+\mathrm{N}$ group and after placed in a specially built size-manipulable cabin as in $\mathrm{S}$ group. Totally for 14 rats in the $\mathrm{C}+\mathrm{N}$ and $\mathrm{N}+\mathrm{S}$ groups were treated with rat nesfatin-1 segment. Body weight of each rat was measured before and after all experimental process.

\section{Blood pressure measurement}

Systolic BP of each rats was measured by a non-invasive tail cuff BP measuring system (Power Lab/8SP data acquisition system, ADInstruments Co., Caringbah, NSW, Australia) before and after all experimental process. All measurements were performed without anesthesia at room temperature in a silent room. The physiological data were analyzed using the LabChart 6.1 Pro software (AD Instruments Co.) (Erken et al. 2013). 


\section{Blood samples and measurements}

At the end of the experimental period, all animals were anesthetized with ketamin/xylazine $\mathrm{HCl}(75 \mathrm{mg} / \mathrm{kg} / 10 \mathrm{mg} / \mathrm{kg}$ intraperitoneally). Blood samples were collected in tubes with EDTA. After centrifugation, plasma of each rat was stored at $-80^{\circ} \mathrm{C}$ until ELISA analysis. Plasma concentrations of AGT (Cusabio Biotech, Cat No CSB-E08565r), ACE2 (Cusabio Biotech, Cat No CSB-E14308r), AngII (Cusabio Biotech, Cat No CSB-E04494r), endothelin-1 (Cusabio Biotech, Cat No CSB-E06979r), eNOS (Cusabio Biotech, Cat No CSB-E08323r), aldosterone (Cusabio Biotech, Cat No CSBE07025r), cortisol (Cusabio Biotech, Cat No CSB-E05112r) and nesfatin-1 (Phoenix Pharma., Cat No EK-003-22) were analyzed by rat ELISA assay kits. Chemiluminescence data were analyzed by an ELISA microplate reader (das, Digital and Analog Systems, Vimercate, MI, Italy).

\section{Statistical analysis}

Statistical analyses were performed by SPSS (Statistical Package for Social Sciences, Chicago, IL, USA) 16.0 package program. All data are given as mean \pm standard deviation (SD). Statistical significances were performed by Wilcoxon, Kruskal-Wallis and Mann-Whitney U tests. Pearson correlation test was used to analyze the correlation between obtained parameters. Differences were considered significant at $p<0.05$.

\section{Results}

\section{Body weights and blood pressures}

We have observed that there are statistically significant decreases of body weight for $\mathrm{S}, \mathrm{C}+\mathrm{N}, \mathrm{N}+\mathrm{S}$ groups compared to their own control $(p=0.028, p=0.018, p=0.018$, respectively; Table 1). As we compare all groups one by one with each other we could identify significant decreases of body weight

Table 1. The level of body weight of rats in Control (C), Stress (S), Nesfatin $(\mathrm{N})$ and Nesfatin+Stress $(\mathrm{N}+\mathrm{S})$ groups before and after nesfatin-1 and stress application

\begin{tabular}{lcccc}
\hline \multirow{2}{*}{ Group } & \multicolumn{2}{c}{ Body weight $(\mathrm{g})$} & \multirow{2}{*}{$p$} & $n$ \\
\cline { 2 - 3 } & before & after & & \\
\hline $\mathrm{C}$ & $353.14 \pm 34.94$ & $353.71 \pm 35.74$ & 0.194 & 7 \\
$\mathrm{~S}$ & $328.14 \pm 11.96$ & $317.42 \pm 16.56$ & 0.028 & 7 \\
$\mathrm{C}+\mathrm{N}$ & $353.71 \pm 35.74$ & $328.85 \pm 41.05$ & 0.018 & 7 \\
$\mathrm{~N}+\mathrm{S}$ & $333.71 \pm 12.48$ & $309.71 \pm 12.16$ & 0.018 & 7 \\
\hline
\end{tabular}

Data are mean \pm SD. $p$ shows the differences between groups (Wilcoxon Test).

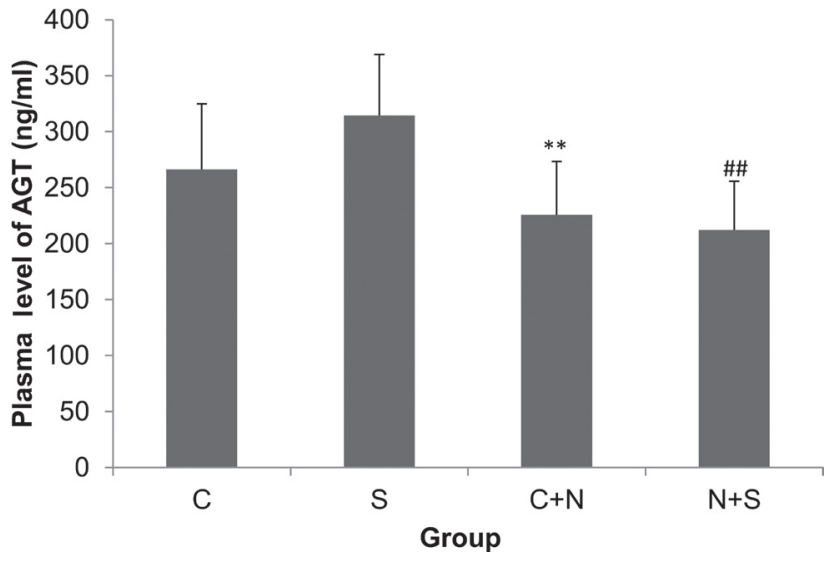

Figure 1. Plasma levels of AGT in Control (C), Stress (S), Control+Nesfatin-1 $(\mathrm{C}+\mathrm{N})$, Nesfatin-1+Stress $(\mathrm{N}+\mathrm{S})$ groups. ${ }^{* *}, \#$,\# $p<$ $0.01 v s . S$ group (Mann Whitney U test). AGT, angiotensinogen.

in $\mathrm{N}+\mathrm{S}$ group compared to $\mathrm{C}$ group $(p=0.017)$. Among all groups statistically significant difference of BP have been observed ( $p=0.001)$. BP for $\mathrm{C}+\mathrm{N}$ group was elevated significantly after nesfatin-1 administration $(p=0.028)$ (Table 2). We could identify that there were significant increases of BP in $\mathrm{C}+\mathrm{N}$ and $\mathrm{N}+\mathrm{S}$ groups compared to $\mathrm{C}$ group and in $\mathrm{C}+\mathrm{N}$ and $\mathrm{N}+\mathrm{S}$ groups compared to $\mathrm{S}$ group $(p=0.001, p=0.005$, $p=0.005, p=0.03$, respectively).

Plasma levels of AGT, ACE2, AngII, aldosterone, cortisol, endothelin-1, eNOS, nesfatin-1

Statistically significant difference has been observed for plasma level of AGT among the C $(266.3 \pm 58.53 \mathrm{ng} / \mathrm{ml})$, $\mathrm{S}(314.37 \pm 54.52 \mathrm{ng} / \mathrm{ml}), \mathrm{C}+\mathrm{N}(225.66 \pm 47.51 \mathrm{ng} / \mathrm{ml})$ and $\mathrm{N}+\mathrm{S}(212.15 \pm 43.64 \mathrm{ng} / \mathrm{ml})$ groups $(p=0.006)$. Comparisons of groups one by one with each other have indicated that plasma levels of AGT were significantly decreased in $\mathrm{C}+\mathrm{N}$ and $\mathrm{N}+\mathrm{S}$ groups compared to $\mathrm{S}$ group $(p=0.007, p=$ 0.002, respectively; Figure 1).

Table 2. The level of blood pressure of rats in Control (C), Stress $(\mathrm{S})$, Nesfatin $(\mathrm{N})$ and Nesfatin+Stress $(\mathrm{N}+\mathrm{S})$ groups before and after nesfatin-1 and stress application

\begin{tabular}{lllll}
\hline \multirow{2}{*}{ Group } & \multicolumn{2}{c}{ Blood pressure $(\mathrm{mmHg})$} & \multirow{2}{*}{$\mathrm{p}$} & \multirow{2}{*}{$n$} \\
\cline { 2 - 3 } & \multicolumn{1}{c}{ before } & \multicolumn{1}{c}{ after } & & \\
\hline $\mathrm{C}$ & $121.37 \pm 4.21$ & $123.09 \pm 4.16$ & 0.237 & 7 \\
$\mathrm{~S}$ & $127.92 \pm 11.85$ & $131.60 \pm 10.31$ & 0.310 & 7 \\
$\mathrm{C}+\mathrm{N}$ & $128.14 \pm 10.25$ & $151.63 \pm 10.2$ & 0.028 & 7 \\
$\mathrm{~N}+\mathrm{S}$ & $128.17 \pm 7.63$ & $146.81 \pm 12.70$ & 0.080 & 7 \\
\hline
\end{tabular}

Data are mean \pm SD. $p$ shows the differences between groups (Wilcoxon Test). 
For plasma level of ACE2 we could also identify statistically significant difference among the $\mathrm{C}(3.36 \pm 0.63 \mathrm{IU} / \mathrm{ml}), \mathrm{S}(3.17$ $\pm 0.61 \mathrm{IU} / \mathrm{ml}), \mathrm{C}+\mathrm{N}(4.43 \pm 1.23 \mathrm{IU} / \mathrm{ml})$ and $\mathrm{N}+\mathrm{S}(4.45 \pm 1.30$ $\mathrm{IU} / \mathrm{ml})$ groups $(p=0.021)$. It has been observed that there were statistically significant increases for plasma levels of ACE2 in $\mathrm{C}+\mathrm{N}$ and $\mathrm{N}+\mathrm{S}$ groups compared to $\mathrm{C}$ group and in $\mathrm{C}+\mathrm{N}$ and $\mathrm{N}+\mathrm{S}$ groups compared to $\mathrm{S}$ group $(p=0.038, p=0.038, p=$ $0.038, p=0.017$, respectively; Figure 2 ).

We could not observe any statistically significant difference for plasma level of AngII among the C $(2.27 \pm 0.52 \mathrm{pg} / \mathrm{ml})$, $\mathrm{S}(3.32 \pm 0.42 \mathrm{pg} / \mathrm{ml}), \mathrm{C}+\mathrm{N}(3.05 \pm 0.87 \mathrm{pg} / \mathrm{ml})$ and $\mathrm{N}+\mathrm{S}(3.04 \pm$ $0.49 \mathrm{pg} / \mathrm{ml}$ ) groups $(p=0.05)$. However, comparisons of groups one by one with each other have indicated that plasma levels of AngII were significantly increased in $\mathrm{S}$ and $\mathrm{N}+\mathrm{S}$ groups compared to C group ( $p=0.01, p=0.03$, respectively; Figure 3 ).

Comparison of plasma level of eNOS among the $\mathrm{C}$ (42.41 $\pm 3.44 \mathrm{mIU} / \mathrm{ml}), \mathrm{S}(52.29 \pm 7.43 \mathrm{mIU} / \mathrm{ml}), \mathrm{C}+\mathrm{N}(41.14 \pm$ $15.61 \mathrm{mIU} / \mathrm{ml})$ and $\mathrm{N}+\mathrm{S}(29.65 \pm 6.83 \mathrm{mIU} / \mathrm{ml})$ group has given a statistically significant difference $(p=0.004)$. It has been observed that plasma level of eNOS was significantly increased in S group compared to C group $(p=0.01)$, significantly decreased in $\mathrm{N}+\mathrm{S}$ group compared to $\mathrm{C}$ and $\mathrm{S}$ groups ( $p=0.009, p=0.001$, respectively; Figure 4$)$.

We could not observe any statistically significant difference for plasma level of nesfatin-1 among the $\mathrm{C}(7.40 \pm 1.63$ $\mu \mathrm{g} / \mathrm{ml}), \mathrm{S}(8.53 \pm 1.71 \mu \mathrm{g} / \mathrm{ml}), \mathrm{C}+\mathrm{N}(9.26 \pm 1.73 \mu \mathrm{g} / \mathrm{ml})$ and $\mathrm{N}+\mathrm{S}(9.45 \pm 1.49 \mu \mathrm{g} / \mathrm{ml})$ groups $(p=0.136)$. However, it has been identified that plasma level of nesfatin-1 in $\mathrm{N}+\mathrm{S}$ group was significantly higher than $\mathrm{C}$ group $(p=0.026)$ (Figure 5).

No statistically significant differences have been found for plasma levels of aldosterone, cortisol, and endothelin-1 among all groups. Plasma level of nesfatin-1 was in positive correlation with plasma level of AGT, ACE2, AngII, eNOS

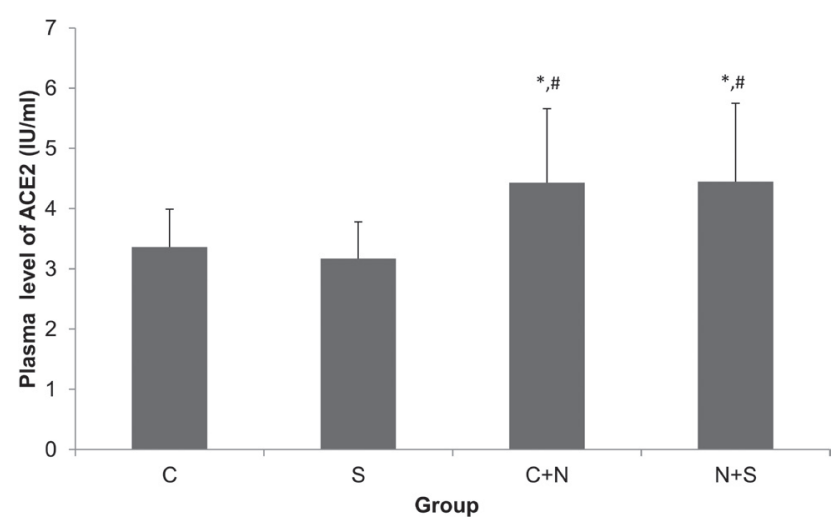

Figure 2. Plasma levels of ACE2 in $\mathrm{C}, \mathrm{S}, \mathrm{C}+\mathrm{N}, \mathrm{N}+\mathrm{S}$ groups. ${ }^{\star} p<$ 0.05 vs. C group (Mann Whitney U test). ${ }^{\#} p<0.05$ vs. S group (Mann Whitney U test). ACE2, angiotensin converting enzyme 2. For more abbreviations see Fig. 1.

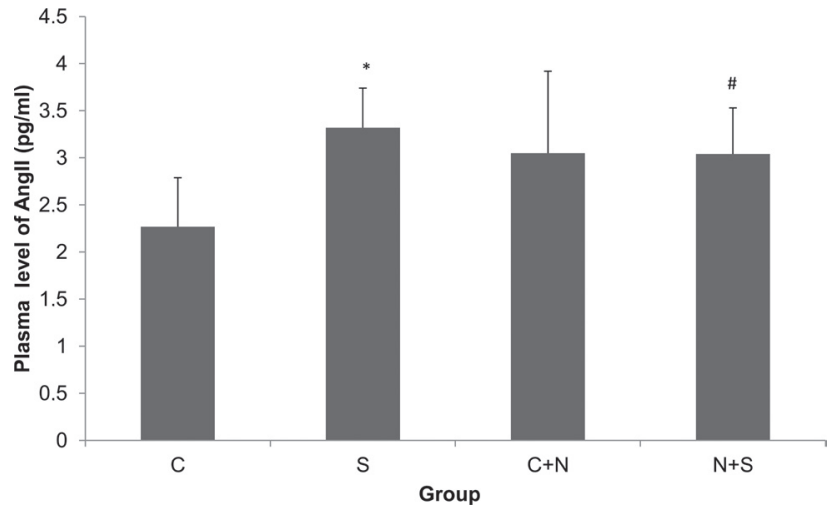

Figure 3. Plasma levels of AngII in C, S, C+N, N+S groups. ${ }^{*}{ }^{*} p<$ 0.05 vs. C group (Mann Whitney U test). AngII, angiotensin II. For more abbreviations see Fig. 1.

and endothelin-1 and in negative correlation with plasma level of aldosterone and cortisol, although not statistically significant (data did not shown).

\section{Discussion}

Hypertension is a multifactorial and important health problem caused by genetic and environmental factors (Stengel and Taché 2010). Cardiovascular responses occur after acute and chronic stress, which can increase the risk of hypertension and cardiovascular diseases (Bechtold et al. 2009). Nesfatin-1 can control appetite in a different pathway than leptin and increases insulin secretion by activation of L-type $\mathrm{Ca}^{2+}$ channels in pancreatic islet beta cells (Cowley and Grove 2006; Nakata et al. 2011). Because of these effects of nesfatin-1, it became a popular therapeutic target. It has been also reported that nesfatin-1 elevates BP (Yosten and Samson 2009; Yamawaki et al. 2012). We suppose that improving our knowledge about nesfatin-1 can help to eliminate its controversial effects during treatment processes. In literature, the effects of nesfatin-1 on appetite have been studied on a large scale, but still we need to know more clues about its physiological effects and the mechanisms of these effects.

In this present study, we have tried to identify the effect of chronic peripheral nesfatin-1 application on BP regulation in normal and in rats exposed to chronic immobilization stress. We have also aimed to indicate the possible relationship between nesfatin-1 and stress condition, BP and related effectors of BP such as AGT, ACE2, AngII, endothelin-1, eNOS, aldosterone and cortisol.

It has been reported that peripheral nesfatin-1 application decreases body weight by inhibiting feeding (Oh-I et al. 2006; Shimizu et al. 2009). We have also observed that 
chronic peripheral nesfatin-1 administration has caused significantly loss of body weight. These results can be taken as a marker about the efficacy of nesfatin-1 application. Chronic restraint stress can cause loss of body weight related with diet or feeding behavior (Harris et al. 1998, 2006; Hennebelle et al. 2012). In the present study, we have also observed a significant decrease of body weight in the $S$ group after experimental process.

It has been identified by different groups that acute stress increases the central level of nesfatin-1 (Goebel et al. 2009; $\mathrm{Xu}$ et al. 2010). However, acute stress does not influence plasma level of nesfatin-1 (Yoshida et al. 2010). Until now, we could not observe any study that examined the effect of chronic restraint stress on plasma level of nesfatin-1. According to our results, we could observe significantly elevated plasma level of nesfatin -1 in $\mathrm{N}+\mathrm{S}$ group compared to $\mathrm{C}$ group. Unfortunately, according to our results, it is not certain whether this elevation is caused by stress or nesfatin-1 administration, although plasma levels of nesfatin-1 were increased in $\mathrm{S}$ and $\mathrm{C}+\mathrm{N}$ groups compared to $\mathrm{C}$ group, but not significantly.

To this point, it has been indicated that chronic stress does not have an effect on BP (Scheuer et al 2007; Bechtold et al. 2009; Scheuer 2010) and nesfatin-1 increases BP (Yosten and Samson 2009, 2010; García-Galiano et al. 2010). Yosten and his colleagues have showed that intracerebroventricular nesfatin-1 administration increases BP (Yosten and Samson 2009) and this effect of nesfatin-1 occurs via sympathetic system activation (Yosten and Samson 2010). Recently, it has been shown that intravenous nesfatin-1 administration can also increase BP by inhibiting nitric oxide (NO) production (Yamawaki et al. 2012). According to our results, we suggest that chronic peripheral nesfatin-1 application can elevate BP in normal and chronic restraint stressed rats.

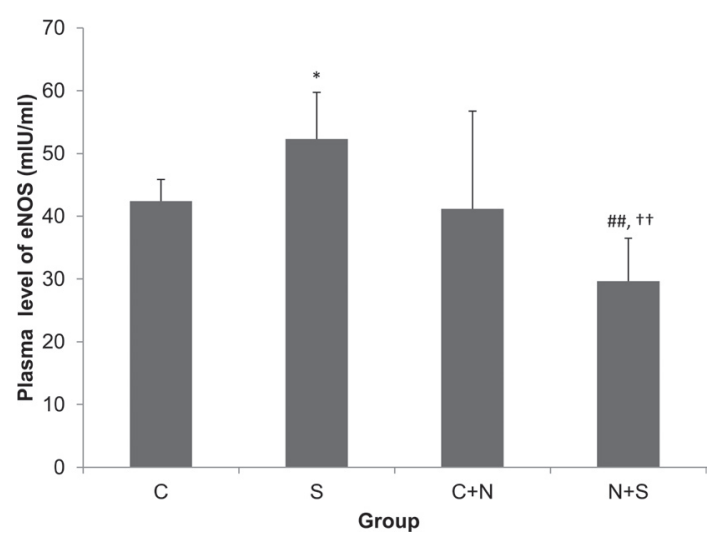

Figure 4. Plasma levels of eNOS in $\mathrm{C}, \mathrm{S}, \mathrm{C}+\mathrm{N}, \mathrm{N}+\mathrm{S}$ groups. ${ }^{*} p<$ 0.05 vs. C group; ${ }^{\#} p<0.01$ vs. $\mathrm{C}$ group; ${ }^{\dagger \dagger} p<0.01$ vs. $\mathrm{S}$ group (Mann Whitney U test). eNOS, endothelial nitric oxide synthase. For more abbreviations see Fig. 1.

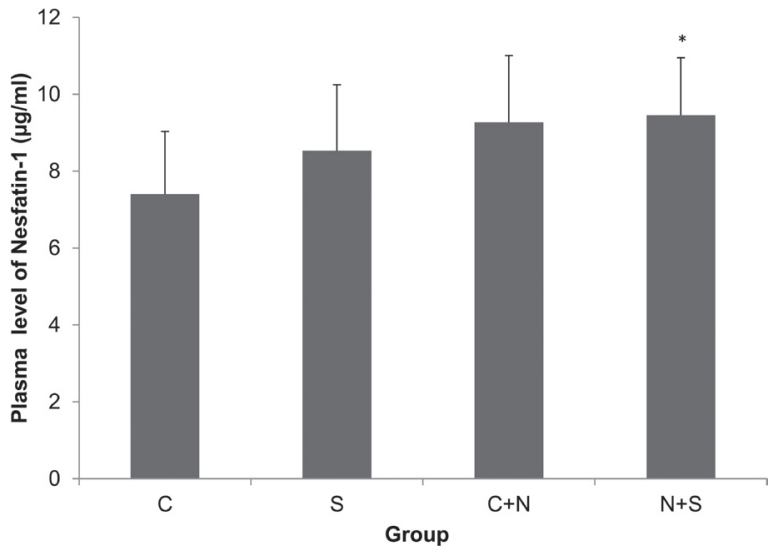

Figure 5. Plasma levels of nesfatin-1 in $\mathrm{C}, \mathrm{S}, \mathrm{C}+\mathrm{N}, \mathrm{N}+\mathrm{S}$ groups. ${ }^{\star} p<0.05 v s$. C group (Mann Whitney U test). For more abbreviations see Fig. 1.

Nesfatin-1 is a rather new subject in research. It should be the reason that there is not any report about its effect on circulating level of AGT, AngII, ACE2, endothelin-1, aldosterone, cortisol and eNOS. Current study have indicated that nesfatin-1 causes decreased plasma level of AGT and increased plasma level of ACE2 in both $\mathrm{C}+\mathrm{N}$ and $\mathrm{N}+\mathrm{S}$ groups. According to this result, we may conclude that nesfatin-1 have possible function in homeostasis in normal and stress conditions. We could observe a significant increase for the plasma level of AngII in $\mathrm{N}+\mathrm{S}$ group compared to C group. On the other hand, it is not clear whether this increase is caused by nesfatin-1 application or not because we also observed an increased plasma level of AngII in $\mathrm{S}$ group compared to $\mathrm{C}$ group. That is why we did not obtain a certain result about the effect of nesfatin-1 on plasma level of AngII. On the other hand, if we focus on decreased plasma level of AngII in N+S group compared to S group, although not statistically significant, this decrease may be caused by nesfatin-1 application, which causes also increased plasma level of ACE2, under chronic stress condition. According to the literature, the main substrate of ACE2 is AngII. Especially in the regulation of cardiovascular homeostasis the function of ACE2 is more important than the function of ACE because the levels of Ang II and Ang 1-7 are mainly regulated by ACE2 for balanced function of renin-angiotensin-aldosterone system (RAAS) (Tikellis and Thomas 2012). That is why we may conclude that decreased plasma level of AngII is in correlation with increased plasma level of ACE2 in $\mathrm{N}+\mathrm{S}$ group.

Acute and chronic stress applications can increase plasma levels of RAAS components (Cody 1997; Saavedra et al. 2004; Goebel et al. 2009; Groeschel and Braam 2011). On the other hand, we could not reach any information about the direct effect of applied stress model on plasma 
level of AGT and ACE2. In this present study, we have observed statistically significant increase in plasma level of AngII in S group compared to C group. Additionally, the increased plasma level of AGT and decreased plasma level of ACE2, although not statistically significant, were observed in $\mathrm{S}$ group compared to $\mathrm{C}$ group. These findings are supplementary to each other. To clarify the effects of applied stress on plasma level of AGT and ACE2, further experiments are needed.

It is very well known that stress response correlates with increased basal blood level of mineralocorticoids and glucocorticoids (McEwen 2007; Ulrich-Lai and Herman 2009; Bechtold et al. 2009). On the other hand, desensitization to repeated stress exposure has been explained linked with recovery of plasma level of corticosterones and adrenocorticotropic hormone (ACTH). Model and duration of applied stress can alter the stress response. At the same time, stress response observations can have diverseness with sampling time (Dal-Zotto et al. 2002, 2003). In the present study, we could not observe any significant changes in plasma levels of aldosterone, cortisol, and endothelin-1 in groups exposed to stress. We think these findings are related with the applied stress model and our sampling time.

It has been reported that peripheral nesfatin-1 administration does not have any effect on stress response (Yoshida et al. 2010). If we consider that stress response is related to plasma levels of aldosteron and cortisol, chronic peripheral nesfatin-1 administration does not have any effect on plasma levels of aldosterone and cortisol. Although the main glucocorticoid in rats is corticosterone, not cortisol as in human (Ulrich-Lai and Herman 2009), we measured plasma level of cortisol. Thus, we have to indicate that this point of our results limits the understanding of the real relationship between the effect of chronic peripheral nesfatin-1 administration on BP and initiation of central stress response. If our results and literature are taken into account, we can conclude that the effect of chronic peripheral nesfatin-1 on BP may not be related with initiated central stress response.

In spite of increased BP by nesfatin-1 application, we could not observe statistically significant differences in plasma level of endothelin-1, aldosterone and cortisol in groups with elevated high BP. We have not assessed the effects of high BP on these parameters due to limitation of experimental design. Thus, we assume that another set of experiment can clarify the effects of high BP.

$\mathrm{NO}$ is known as an important vasodilator. It causes vasodilatation via inhibiting the effects of vasoconstrictors such as AngII and endothelin-1 (Rubbo et al. 2002; Davignon and Ganz 2004). NO is synthesized by a family of NO synthases (NOSs) isoforms that are neuronal, endothelial and inducible NOS (referred respectively; nNOS, eNOS and iNOS) (Kleinbongard et al. 2006). Although all iso- forms of NOSs have regulatory function on cardiovascular system, eNOS has a special importance as a $\mathrm{BP}$ regulator via vasodilator effect on blood vessels (Balligand et al. 2009). Circulating level of eNOS can be derived from vascular endothelium and red blood cells (RBCs) and has an importance in cardiovascular pathophysiology because of its contribution to the circulating NO pool; on the other hand, the origin of NO synthesis within the plasma (RBCs or non-RBCs) cannot be differentiated (Kleinbongard et al. 2006; Cortese-Krott and Kelm 2014). In this present study, we cannot explain the exact source of eNOS apart from the total amount of eNOS. We have observed that chronic restraint stress significantly increases plasma level of eNOS. Based on our knowledge, increased vascular endothelial growth factor (VEGF) causes increased tumor eNOS level in chronic-stressed mice (Barbieri et al. 2012). Additionally, RBCs can contribute NO bioavailability by releasing ATP under hypoxia and shear stress condition. Thereby, RBCs induce eNOS dependent vasorelaxation and increase in blood flow under stress-related conditions (Cortese and Kelm 2014). Collectively, we can conclude that applied stress model can cause elevated plasma level of eNOS in rats.

Recently, it has been shown that intravenous nesfatin-1 application increases vessel contraction via repressing NO production and subsequently causes high BP (Yamawaki et al. 2012). According to our results, it is highly possible that chronic peripheral nesfatin-1 decreases plasma level of eNOS specifically in rats subjected to chronic restraint stress. Consistent with these observations, eNOS and NO may be the key factors for chronic peripheral nesfatin-1 effect on BP especially in stressed condition.

In conclusion, chronic peripheral nesfatin-1 administration can cause high BP in normal and in rats subjected to chronic restraint stress. This effect of nesfatin- 1 is not affected by stimulated central stress response, elevated level of AGT, AngII and decreased level of ACE2 under normal and stressed conditions. Additionally, the effect of chronic peripheral nesfatin-1 administration on BP can be related with decreased eNOS production especially in stressed condition. Nesfatin-1 has a raising attention as a therapeutic agent for various diseases. We believe knowing more about the effects of nesfatin-1 on different physiological parameters in different conditions can provide benefits for the effective usage of nesfatin-1 in therapeutic processes. Thus, we suppose further experiments are necessary on this subject.

Declaration of interest. The authors report no conflicts of interest.

Acknowledgment. This study was supported by Pamukkale University Research Fund (Project No. 2011SBE005). 


\section{References}

Agyemang C., van Hooijdonk C., Wendel-Vos W., Ujcic-Voortman J. K., Lindeman E., Stronks K., Droomers M. (2007): Ethnic differences in the effect of environmental stressors on blood pressure and hypertension in the Netherlands. BMC Public Health 7, 118

http://dx.doi.org/10.1186/1471-2458-7-118

Balligand J. L., Feron O., Dessy C. (2009): eNOS activation by physical forces: from short-term regulation of contraction to chronic remodeling of cardiovascular tissues. Physiol. Rev. 89, 481-534 http://dx.doi.org/10.1152/physrev.00042.2007

Barbieri A., Palma G., Rosati A., Giudice A., Falco A., Petrillo A., Petrillo M., Bimonte S., Di Benedetto M., Esposito G. et al. (2012): Role of endothelial nitric oxide synthase (eNOS) in chronic stress-promoted tumour growth. J. Cell. Mol. Med. 16, 920-926 http://dx.doi.org/10.1111/j.1582-4934.2011.01375.x

Bechtold A. G., Patel G., Hochhaus G., Scheuer D. A. (2009): Chronic blockade of hindbrain glucocorticoid receptors reduces blood pressure responses to novel stress and attenuates adaptation to repeated stress. Am. J. Physiol. Regul. Integr. Comp. Physiol. 296, 1445-1454 http://dx.doi.org/10.1152/ajpregu.00095.2008

Bhatia N., Maiti P. P., Choudhary A., Tuli A., Masih D., Khan M. M. U., Ara T., Jaggi A. S. (2011): Animal models in the study of stress: A review. NSHM J. Pharm. Healthcare Manage 02, 42-50 http://www.nshm.com/pdf/Animal_models_study_of_stress. pdf

Cody R. J. (1997): The sympathetic nervous system and the reninangiotensin-aldosterone system in cardiovascular disease. Am. J. Cardiol. 13, 9J-14J http://dx.doi.org/10.1016/S0002-9149(97)00832-1

Cortese-Krott M. M., Kelm M. (2014): Endothelial nitric oxide synthase in red blood cells: Key to a new erythrocrine function? Redox Biol. 2, 251-258 http://dx.doi.org/10.1016/j.redox.2013.12.027

Cowley M. A., Grove K. L. (2006): To be or NUCB2, is nesfatin the answer? Cell. Metab. 4, 421-422 http://dx.doi.org/10.1016/j.cmet.2006.11.001

Dal-Zotto S., Martí O., Armario A. (2002): Is repeated exposure to immobilization needed to induce adaptation of the hypothalamic-pituitary-adrenal axis? Influence of adrenal factors. Behav. Brain Res. 129, 187-195 http://dx.doi.org/10.1016/S0166-4328(01)00340-0

Dal-Zotto S., Martí O., Armario A. (2003): Glucocorticoids are involved in the long-term effects of a single immobilization stress on the hypothalamic-pituitary-adrenal axis. Psychoneuroendocrinology 28, 992-1009 http://dx.doi.org/10.1016/S0306-4530(02)00120-8

Davignon J., Ganz P. (2004): Role of endothelial dysfunction in atherosclerosis. Circulation 109, 27-32 http://dx.doi.org/10.1161/01.CIR.0000131515.03336.f8

Erken H. A., Erken G., Genç O. (2013): Blood pressure measurement in freely moving rats by the tail cuff method. Clin. Exp. Hypertens. 35, 11-15 http://dx.doi.org/10.3109/10641963.2012.685534
García-Galiano D., Navarro V. M., Gaytan F., Tena-Sempere M. (2010): Expanding roles of NUCB2/nesfatin-1 in neuroendocrine regulation. J. Mol. Endocrinol. 45, 281-290 http://dx.doi.org/10.1677/JME-10-0059

Goebel M., Stengel A., Wang L., Taché Y. (2009): Restraint stress activates nesfatin- 1 immunoreactive brain nuclei in rats. Brain Res. 1300, 114-124 http://dx.doi.org/10.1016/j.brainres.2009.08.082

Groeschel M., Braam B. (2011): Connecting chronic and recurrent stress to vascular dysfunction: no relaxed role for the renin-angiotensin system. Am. J. Physiol. Renal. Physiol. 300, F1-10 http://dx.doi.org/10.1152/ajprenal.00208.2010

Han S., Chen X., Cox B., Yang C. L., Wu Y. M., Naes L., Westfall T. (1998): Role of neuropeptide $Y$ in cold stress-induced hypertension. Peptides 19, 351-358 http://dx.doi.org/10.1016/S0196-9781(97)00297-0

Harris R. B., Zhou J., Youngblood B. D., Rybkin I. I., Smagin G. N., Ryan D. H. (1998): Effect of repeated stress on body weight and body composition of rats fed low and high-fat diets. Am. J. Physiol. 275, 1928-1938

http://ajpregu.physiology.org/content/ajpregu/275/6/R1928. full.pdf

Harris R. B., Palmondon J., Leshin S., Flatt W. P., Richard D. (2006): Chronic disruption of body weight but not of stress peptides or receptors in rats exposed to repeated restraint stress. Horm. Behav. 49, 615-625 http://dx.doi.org/10.1016/j.yhbeh.2005.12.001

Hennebelle M., Balasse L., Latour A., Champeil-Potokar G., Denis S., Lavialle M., Gisquet-Verrier P., Denis I., Vancassel S. (2012): Influence of omega-3 Fatty Acid status on the way rats adapt to chronic restraint stress. PLoS One 7, e42142 http://dx.doi.org/10.1371/journal.pone.0042142

Kearney P. M., Whelton M., Reynolds K., Muntner P., Whelton P. K., He J. (2005): Global burden of hypertension: analysis of worldwide data. Lancet 365, 217-223 http://dx.doi.org/10.1016/S0140-6736(05)17741-1

Kleinbongard P., Schulz R., Rassaf T., Lauer T., Dejam A., Jax T., Kumara I., Gharini P., Kabanova S., Ozüyaman B. et al. (2006): Red blood cells express a functional endothelial nitric oxide synthase. Blood 107, 2943-2951

http://dx.doi.org/10.1182/blood-2005-10-3992

McEwen B. S. (2007): Physiology and neurobiology of stress and adaptation: central role of the brain. Physiol. Rev. 87, 873-904 http://dx.doi.org/10.1152/physrev.00041.2006

Nakata M., Manaka K., Yamamoto S., Mori M., Yada T. (2011): Nesfatin-1 enhances glucose-induced insulin secretion by promoting $\mathrm{Ca}(2+)$ influx through L-type channels in mouse islet $\beta$-cells. Endocr. J. 58, 305-313 http://dx.doi.org/10.1507/endocrj.K11E-056

Oh-I S., Shimizu H., Satoh T., Okada S., Adachi S., Inoue K., Eguchi H., Yamamoto M., Imaki T., Hashimoto K. et al. (2006): Identification of nesfatin- 1 as a satiety molecule in the hypothalamus. Nature 12, 709-712 http://dx.doi.org/10.1038/nature05162

Rubbo H., Trostchansky A., Botti H., Batthyány C. (2002): Interactions of nitric oxide and peroxynitrite with low-density lipoprotein. Biol. Chem. 383, 547-552 http://dx.doi.org/10.1515/BC.2002.055 
Saavedra J. M., Ando H., Armando I., Baiardi G., Bregonzio C., Jezova M., Zhou J. (2004): Brain angiotensin II, an important stress hormone: regulatory sites and therapeutic opportunities. Ann. N.Y. Acad. Sci. 1018, 76-84 http://dx.doi.org/10.1196/annals.1296.009

Scheuer D. A., Bechtold A. G., Vernon K. A. (2007): Chronic activation of dorsal hindbrain corticosteroid receptors augments the arterial pressure response to acute stress. Hypertension 49, 127-133 http://dx.doi.org/10.1161/01.HYP.0000250088.15021.c2

Scheuer D. A. (2010): Regulation of the stress response in rats by central actions of glucocorticoids. Exp. Physiol. 95, 26-31 http://dx.doi.org/10.1113/expphysiol.2008.045971

Shimizu H., Oh-I S., Hashimoto K., Nakata M., Yamamoto S., Yoshida N., Eguchi H., Kato I., Inoue K., Satoh T. et al. (2009): Peripheral administration of nesfatin-1 reduces food intake in mice: the leptin-independent mechanism. Endocrinology 150, 662-671 http://dx.doi.org/10.1210/en.2008-0598

Stengel A., Taché Y. (2010): Nesfatin-1 role as possible new potent regulator of food intake. Regul. Pept. 163, 18-23 http://dx.doi.org/10.1016/j.regpep.2010.05.002

Tikellis C., Thomas M. C. (2012): Angiotensin-converting enzyme 2 (ACE2) is a key modulator of the renin angiotensin system in health and disease. Int. J. Pept. 2012, 256294 http://dx.doi.org/10.1155/2012/256294

Ulrich-Lai Y. M., Herman J. P. (2009): Neural regulation of endocrine and autonomic stress responses. Nat. Rev. Neurosci. 10, 397-409 http://dx.doi.org/10.1038/nrn2647

Vyas A., Mitra R., Rao S. B. S., Chattarji S. (2002): Chronic stress induces contrasting patterns of dendritic remodeling in hippocampal and amygdaloid neurons. J. Neurosci. 22, 6810-6818

Xu L., Bloem B., Gaszner B., Roubos E. W., Kozicz T. (2010): Stressrelated changes in the activity of cocaine and amphetamine regulated transcript and nesfatin neurons in the midbrain non-preganglionic Edinger-Westphal nucleus in the rat. Neuroscience 170, 478-488

http://dx.doi.org/10.1016/j.neuroscience.2010.07.001

Yamawaki H., Takahashi M., Mukohda M., Morita T., Okada M., Hara Y. (2012): A novel adipocytokine, nesfatin-1 modulates peripheral arterial contractility and blood pressure in rats. Biochem. Biophys. Res. Commun. 418, 676-681 http://dx.doi.org/10.1016/j.bbrc.2012.01.076

Yoshida N., Maejima Y., Sedbazar U., Ando A., Kurita H., Damdindorj B., Takano E., Gantulga D., Iwasaki Y., Kurashina T. et al. (2010): Stressor-responsive central nesfatin-1 activates corticotropinreleasing hormone, noradrenaline and serotonin neurons and evokes hypothalamic-pituitary-adrenal axis. Aging 2, 775-784

Yosten G. L., Samson W. K. (2009): Nesfatin-1 exerts cardiovascular actions in brain: possible interaction with the central melanocortin system. Am. J. Physiol. Regul. Integ. Comp. Physiol. 297, 330-336 http://dx.doi.org/10.1152/ajpregu.90867.2008

Yosten G. L., Samson W. K. (2010): The anorexigenic and hypertensive effects of nesfatin- 1 are reversed by pretreatment with an oxytocin receptor antagonist. Am. J. Physiol. Regul. Integr. Comp. Physiol. 298, R1642-1647 http://dx.doi.org/10.1152/ajpregu.00804.2009

Received: March 17, 2014

Final version accepted: October 1, 2014

First published online: December 11, 2014 